\title{
In situ laccase-assisted overdyeing of denim using flavonoids
}

\author{
Clara Guimarães, Suyeon Kim, Carla Silva and Artur Cavaco-Paulo \\ University of Minho, Textile Engineering Department, Guimarães, Portugal
}

\begin{abstract}
A laccase-mediated system for denim overdyeing using phenolic compounds was developed. Laccase from ascomycete Myceliophthora thermophila was able to oxidize phenolic compounds such as catechol and catechin and mediate their attachment to denim surfaces. Laccase-generated polymers gave rise to new coloration states from dark brown to green-yellow and replaced dyes in the overdyeing process. Process parameters, such as enzyme dosage, incubation time and presence of mediator, were studied by considering a compromise between the highest overdyeing level and lower energy/products consumption ( $2 \mathrm{U} / \mathrm{mL}$ laccase; $4 \mathrm{~h}$ incubation in the absence of mediator). Enzyme-generated polymers were followed by UV/Vis spectrophotometry and their level of attachment to denim surfaces was evaluated by means of spectral values quantification $[k / s$, Kubelka-Munk relationship ( $k=$ absorption coefficient, $s=$ scattering coefficient)]. Overdyeing of denim with phenolics, such as catechol or catechin, was successfully achieved with acceptable levels in terms of durability.
\end{abstract}

Received 31 March 2011

Revised 9 May 2011

Accepted 17 June 2011

Keywords: Biocatalysis · Biopolymers · Catechol · Catechin · Textiles

\section{Introduction}

Dyed cellulosic textiles, which are commonly known as "denim", are used in the fabrication of a large variety of products, in particular, "blue" jeans and skirts. Denim textiles are generally constructed with a warp yarn (dyed with indigo) and a filling yarn (unbleached or white yarn) [1]. A further class of denim-containing products are garments that may be characterised as "overdyed" denim.

Overdyeing of denim is actively performed to create new shades of textiles imposed by the consumer's desire [2]. Such products may be produced by subjecting the denim to a further dyeing step. This step acts to primarily dye the filling yarn of the desized denim, but also to impart some degree of dyeing to the previously dyed warp yarn. For such dyeing operations, direct dyes are generally ap-

\footnotetext{
Correspondence: Dr. Artur Cavaco-Paulo, Textile Engineering Department, University of Minho, Campus de Azurém, 4800-058 Guimarães, Portugal E-mail: artur@det.uminho.pt

Abbreviations: ABTS, 2,2'-azino-bis-(3-ethyl benzothiazoline-6-sulfonic acid); $k / s$, Kubelka-Munk relationship ( $k=$ absorption coefficient, $s=$ scattering coefficient)
}

plied at high temperatures with high quantities of salt [1, 2]. Considering several drawbacks related with the use of dyes, new approaches to replace them with environmentally friendly products have been studied. A denim washing process was developed that used specific enzymes, namely, cellulases, to give a commercial look to denim jeans [3-7]. Several enzymatic methods were developed for denim overdyeing by contacting the textile with enzymes in the presence of a dye to impart a stonewashed and overdyed effect [2]. Enzymatic polymerisation is one application that has drawn considerable attention because of its ability to form polymers that can be used as "dyes" on denim overdyeing. Laccase is one of the catalysts able to polymerise phenolics and flavonoids, such as catechol or catechin. This enzyme catalyses the oxidation of phenolic compounds by using molecular oxygen as an electron acceptor. The phenolic compounds form phenoxy radicals that become quinone intermediates in the second stage of oxidation. These quinones are very reactive species and undergo non-enzymatic radical coupling to form covalent bonds involving polymerisation or cross-linking of phenolic monomers [8-11]. These polymers are high-molecular-weight compounds 
with lower solubility, but higher stability than specific monomers [12]. Moreover, the oxidised phenols usually result in high-coloured after enzymatic oxidation due to the formation of big conjugated structures along the main chain [13].

As polyphenols, poly(catechol) and poly(catechin) are susceptible to enzymatic and non-enzymatic oxidations, giving rise to a variety of dimeric, oligomeric and polymeric products [9, 14-19] and can replace dyes in denim overdyeing by in situ oxidative polymerisation with laccase. Several works have been reported about the oxidation of phenols by laccase and their attachment to lignocellulosic fibres [20-23].

Herein, laccase from ascomycete Myceliophthora thermophila was used as a catalyst to oxidise catechol and catechin and obtain polymers capable of in situ overdying the surface of denim fabrics with acceptable levels in terms of durability.

\section{Materials and methods}

\subsection{Enzyme, fabrics and reagents}

Laccase (EC 1.10.3.2) from the ascomycete $M$. thermophila, Novozym ${ }^{\circledR} 51003$ (305 U/mL), was obtained from Novozymes (Bagsvaerd, Denmark). The indigo-dyed and enzymatic-desized denim fabrics were kindly supplied by Vicunha Textil SA, Brazil, and used for laccase-assisted enzymatic colouration. Lutensol AT25, an anionic surfactant, was kindly supplied by BASF (Ludwigshafen, Germany). The phenolic compounds, namely, catechol, catechin and other chemicals, were commercially purchased at analytical grade from Sigma, Spain, and used without further purification.

\subsection{Laccase activity test}

Standard assays of laccase activity were performed spectrophotometrically by measuring the enzymat-

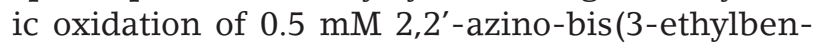
zthiazoline-6-sulfonic) acid (ABTS) at $420 \mathrm{~nm}$ [22]. One unit of laccase (U) was defined as the amount of enzyme required to oxidise $1 \mu \mathrm{mol}$ of ABTS per minute. Each assay was done in triplicate.

\subsection{UV/Vis spectrophotometry}

Molecular reorganisation of catechol and catechin catalysed by laccase was studied for different periods of incubation, namely, 0, 2, 4, 6 and $24 \mathrm{~h}$. The spectrum of each solution was monitored by UV/Visible spectrophotometry using a diode-array J\&M Tidas spectrophotometer (J\&M Analytische
Mess und Regeltechnik GmbH, Germany). The catechol and catechin solutions without laccase were also monitored as reference samples. The assay was performed in duplicate.

\subsection{Laccase-assisted enzymatic overdyeing}

Catechol and catechin were used as the main components to overdye the denim fabrics. Laccase was used as the catalyst to oxidise these products, promoting their in situ polymerisation. Several reaction factors, such as laccase dosages, incubation time and presence of mediator, were considered for the optimisation of denim overdyeing. Phenolic compound solutions $(0.01 \mathrm{M})$ were prepared by using $0.1 \mathrm{M}$ sodium acetate buffer at $\mathrm{pH}$ 5. In each reaction pot, containing $100 \mathrm{~mL}$ of phenolic solution, $5 \mathrm{~g}$ of desized denim fabrics and different concentrations of laccase were placed.

\subsubsection{Effect of laccase dosage}

Different dosages $(0,1,2$ and $5 \mathrm{U} / \mathrm{mL})$ of laccase were introduced in each incubation pot, containing $0.01 \mathrm{M}$ catechol and catechin, respectively. Incubation was carried out at the optimum temperature of laccase $\left(50^{\circ} \mathrm{C}\right)$, for $4 \mathrm{~h}$ by using an Ahiba spectradye Datacolor dyeing machine at $40 \mathrm{rpm}$, providing vertical agitation. After completing incubation, the denim samples were washed thoroughly to remove unattached phenolic compounds and enzyme from the surface, using a Lutensol solution (anionic surfactant) $1 \mathrm{~g} / \mathrm{L}$ for $10 \mathrm{~min}$ at $100^{\circ} \mathrm{C}$ with an Ahiba dyeing machine.

\subsubsection{Effect of incubation time}

Different periods of incubation were studied for the enzymatic oxidation of phenolic compounds. Denim samples were incubated with phenolic compounds in the presence and absence of laccase for 2, 4, 6 and $24 \mathrm{~h}$. Afterwards, the washing process was followed as described previously.

\subsubsection{Effect of mediator}

Syringaldehyde $(0.001 \mathrm{M})$ was used as a laccase mediator and was included in the reaction pots. As a reference, the denim fabrics were also incubated with phenolic solutions in the presence of syringaldehyde without laccase addition.

\subsection{Colour strength estimation}

The influence of the factors mentioned before were evaluated by means of colour strength estimation $(k / s) . k / s$ values were obtained by using a Datacolor apparatus at standard illuminant D65 with the Kubelka-Munk equation (Eq. 1), in which $K$ is the 
absorbance coefficient, $S$ is the scattering coefficient and $R$ is the reflectance ratio. The data are the sum of all $\mathrm{k} / \mathrm{s}$ values obtained at the wavelength range $400-700 \mathrm{~nm}$. The measurements were done in triplicate and the data presented are the mean values of these measurements.

$k / s=(1-R)^{2} / 2 R$

\subsection{Durability of denim overdyeing}

The durability of phenolic polymers attached to the surface of denim was tested in terms of a colour-resistance test, that is, washing, rubbing and light fastness. The standard test method for colour fastness to domestic and commercial laundering (ISO 105-C06) was followed with and without $\mathrm{NaBO}_{3}$ [19]. Wet and dry rubbing fastness was measured following the standard test method using a crockmeter: ASTM D2054-99 [20]. The light fastness was performed by deposition of denim in the Accelerated Weathering Tester (QUV) Spray LU-0819 from Q-PANEL, equipped with UVA 340 lamp, at $70{ }^{\circ} \mathrm{C}$ and irradiation at $77 \mathrm{~W} / \mathrm{m}^{2}$ for light fastness test. The QUV test chamber simulated weather conditions. Exposure cycles of 8 or $24 \mathrm{~h}$ were applied on samples until remarkable colour degradation was observed. Each flat plaque was holding two samples of standard sizes $(75 \times 150 \mathrm{~mm})$.

\subsection{Tensile resistance}

The tensile strength of overdyed denim fabrics was further studied by maximum force and elongation measurements. This property was measured by following the procedure NP EN ISO 13934-1:2001 Tensile properties of fabrics - part 1: determination of maximum force and elongation at maximum force using the strip method.

\subsection{Wettability test}

The hydrophilic/-phobic properties of overdyed denim were studied by water contact angle (CA) measurements with deionised water droplets on the treated fabric surfaces at room temperature. The data were determined by averaging values after measuring at three different points on each fabric sample. A dosing volume of water droplet was set as $15 \mu \mathrm{L}$ using a Hamilton $500-\mu \mathrm{L}$ syringe type. Conditions for measurement were selected as ellipse fitting. The sample images were captured at the first second of water droplet onto samples by using a SCA-20 live camera.

\section{Results and discussion}

Laccase catalyses the oxidation of phenols by oneelectron oxidation, consuming molecular oxygen. The phenolic compounds form phenoxy radicals that turn into quinone intermediates in the second stage of oxidation. These quinones are very reactive and undergo non-enzymatic radical coupling reaction to form covalent bonds involving polymerisation or cross-linking of phenolic monomers $[8,15]$. Thus, it seemed reasonable to us that laccase could oxidise catechol and catechin to obtain polymers able to cover the denim surface.

The molecular reorganisation of catechol and catechin $(0.01 \mathrm{M}$ each) catalysed by $2 \mathrm{U} / \mathrm{mL}$ laccase was studied for different periods of incubation, that is, $0,2,4,6$ and $24 \mathrm{~h}$ and the spectrum of each solution was monitored and interpreted by UV/Vis spectrophotometry. The catechol and catechin solutions without laccase were also monitored as reference samples (Fig. 1). Observing the results obtained, it was clear that laccase was highly active for the oxidative polymerisation of the mentioned phenolic compounds. UV/Vis spectra show a sharp peak at around 230 and $280 \mathrm{~nm}$ due to $\pi-\pi^{*}$ transitions of the aromatic fragment of the monomer phenolic compounds in acetate buffer. After the introduction of laccase, different behaviour was observed for both catechol and catechin spectra. For catechin, a new peak at around $400 \mathrm{~nm}$ was observed. This peak corresponds to the formation of poly(catechin) by enzymatic oxidation. For catechol, laccase action results in a new peak at around $300 \mathrm{~nm}$, corresponding to monomer oxidation and further oxidative polymerisation (4 $\mathrm{h}$ of incubation). The large broad peak observed is mainly due to the colour intensity increase during enzymatic polymerisation. The colour change from uncoloured to dark brown during enzymatic oxidation may be explained by the formation of hydroquinones, which are consecutively oxidised by laccase, then form dimers, oligomers and polymers $[22,23,24]$. It is also interesting to notice that, especially for catechin, the band intensity reaches a saturation level after $4 \mathrm{~h}$ of incubation, meaning that after this period no more oxidation occurs. The enzyme activity decreases as well as the amount of quinones available to react, decreasing therefore the possibility of polymer formation.

Generally, overdyeing is processed on colourised warp and non-colourised weft (filling yarn) surfaces. In this work, the warp-dyed denim fabrics (indigo dyed) were modified in terms of overdyeing by extra colour introduction. For this, catechol and catechin were oxidised by laccase in situ at the sur- 

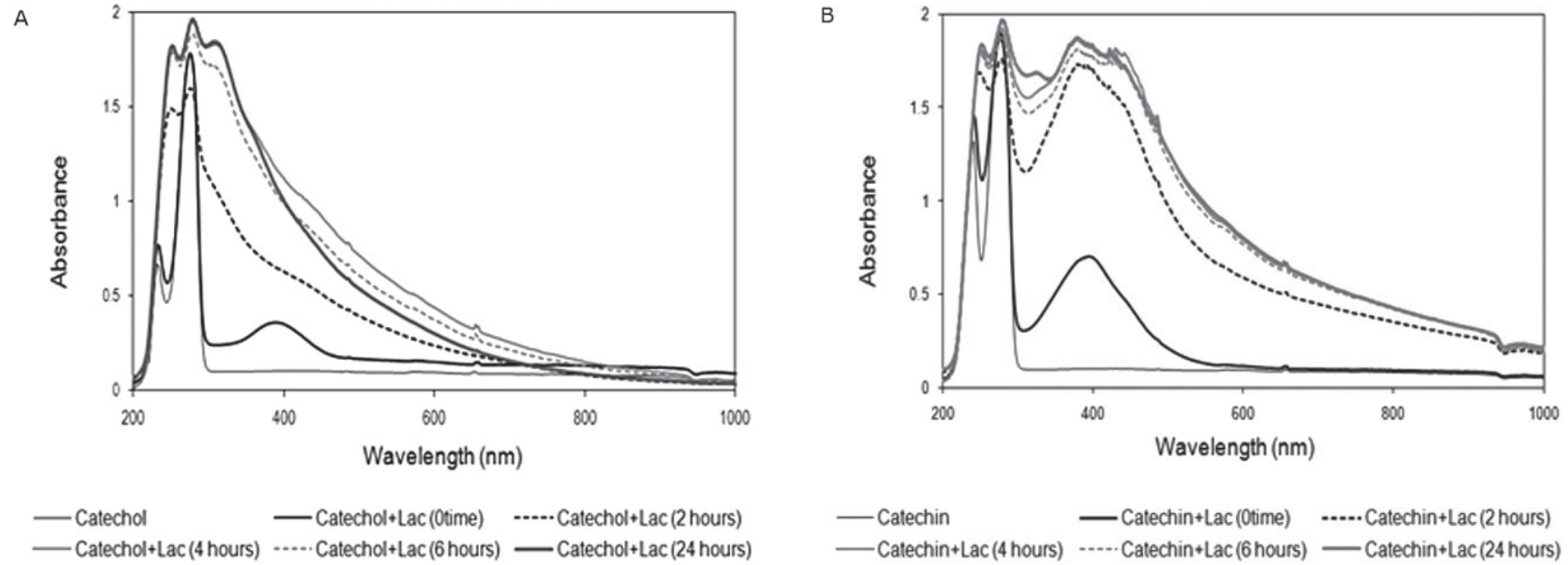

Figure 1. UV/Vis spectroscopic analysis of $(\mathbf{A})$ catechol and $(\mathbf{B})$ catechin $(0.01 \mathrm{M}$ each) oxidation in the presence of laccase $(2 \mathrm{U} / \mathrm{mL}) \mathrm{monitored}$ at $0,2,4$, 6 and $24 \mathrm{~h}$; solutions of catechin and catechol without laccase addition were used as controls.

face of the denim fabrics, resulting in darker overdyed surfaces due to polymer deposition.

Process optimisation was carried out by studying several parameters, such as incubation time, enzyme dosage, and presence or absence of mediator. All of these parameters were evaluated by considering the colour strength after treatment by means of $\mathrm{k} / \mathrm{s}$ determination. Firstly, the enzyme dosage was optimised. Different concentrations of laccase were introduced in each incubation pot, containing $0.01 \mathrm{M}$ catechol and catechin, respectively, at $50^{\circ} \mathrm{C}$, for $4 \mathrm{~h}$ by using an Ahiba dyeing machine at $40 \mathrm{rpm}$, providing vertical agitation. After completing incubation, the denim samples were washed thoroughly to remove unattached phenolic compounds and enzyme from the surface, using a $1 \mathrm{~g} / \mathrm{L}$ Lutensol AT 25 for $10 \mathrm{~min}$ at $100^{\circ} \mathrm{C}$ with an Ahiba dyeing machine. The control reactions were performed without laccase addition. The results presented in Fig. 2 show that in the absence of laccase no overdyeing was verified. Samples without catechol or catechin in absence of laccase, also revealed no overdyeing. On the other hand, when laccase is included in the system, a colour increase is detected. This is due to polymer generation and deposition at the surface of the denim, giving rise to a darker denim surface. It can also be depicted that the highest colouration is obtained when $2 \mathrm{U} / \mathrm{mL}$ of laccase is used, for both compounds under consideration. Above this value, the colour intensity is lower, probably due to saturation phenomena attributed either to the phenol or to the denim fabric. A high dose of laccase can saturate the phenolic compound, hindering normal quinone formation and at the same time cover the possible sites of polymer attachment at the denim surface (Fig. 2A).

At the same time, and considering the thermal stability of laccase, a preliminary study was performed to evaluate laccase behaviour with time at $50^{\circ} \mathrm{C}$ (optimum temperature). For this, the enzyme $\left(2 \mathrm{U} / \mathrm{mL}\right.$ ) was incubated at $50^{\circ} \mathrm{C}$ in sodium acetate buffer ( $\mathrm{pH}$ 5) using a water bath. The activity loss was evaluated by the ABTS method and about $60 \%$ activity loss was detected after incubation for $2 \mathrm{~h}$. The enzyme loses all of its activity after incubation for $24 \mathrm{~h}$ under the considered conditions (data not shown). However, other authors proved that laccase, generally applied in oxidation of phenolic substrates for long reaction periods, is not deactivated in the presence of polymeric substrates. Moreover, laccase catalysis takes place in combination with non-enzymatic pathways, maintaining, therefore, its stability for longer periods of time [24]. Considering energy-saving concerns, the process time is an important factor to take into consideration. For this, the time of enzymatic overdyeing of denim was studied (Fig. 2B). Denim samples were incubated with phenolic compounds in the presence and absence of laccase $(2 \mathrm{U} / \mathrm{mL}$ ) for 2,4 , 6 , and $24 \mathrm{~h}$. Afterwards, the washing process was followed as described previously. Figure 2B evidences the colour behaviour of overdyed samples. In the case of catechol, it seems clear that the optimum time to obtain the highest overdyeing level is incubation for $4 \mathrm{~h}$. From this point, the colour intensity decreased not only due to the saturation phenomena already mentioned, but also due to the highest decrease in activity of laccase in the presence of this substrate. Moreover, the adsorption/ 
A

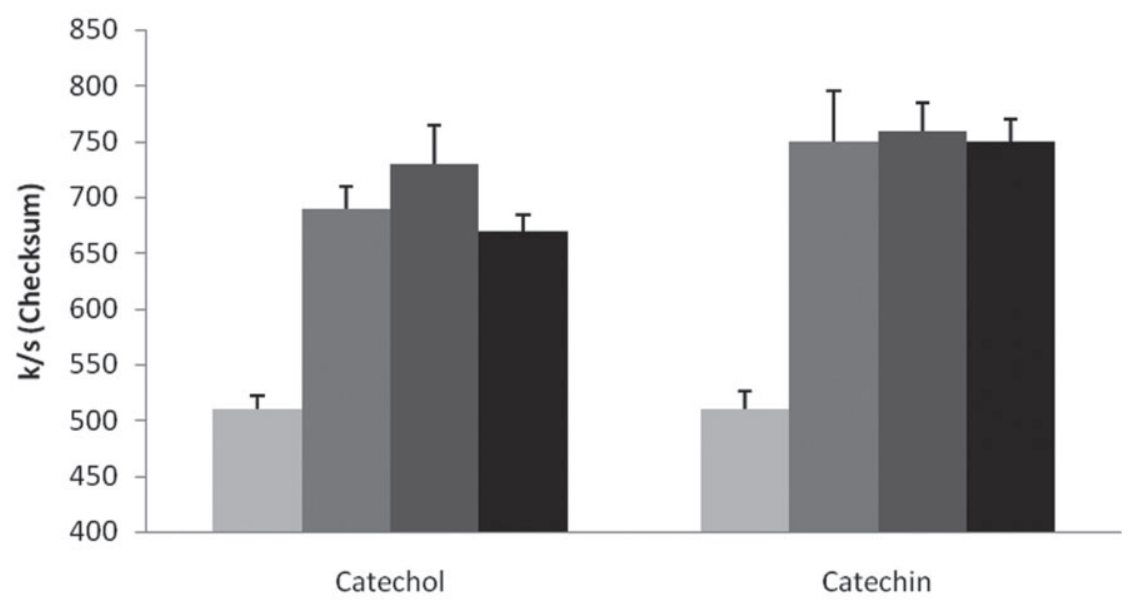

muntreated $\quad \square 1 \mathrm{U} / \mathrm{mL} \quad \square 2 \mathrm{UL} / \mathrm{mL} \quad \square 5 \mathrm{U} / \mathrm{mL}$

B

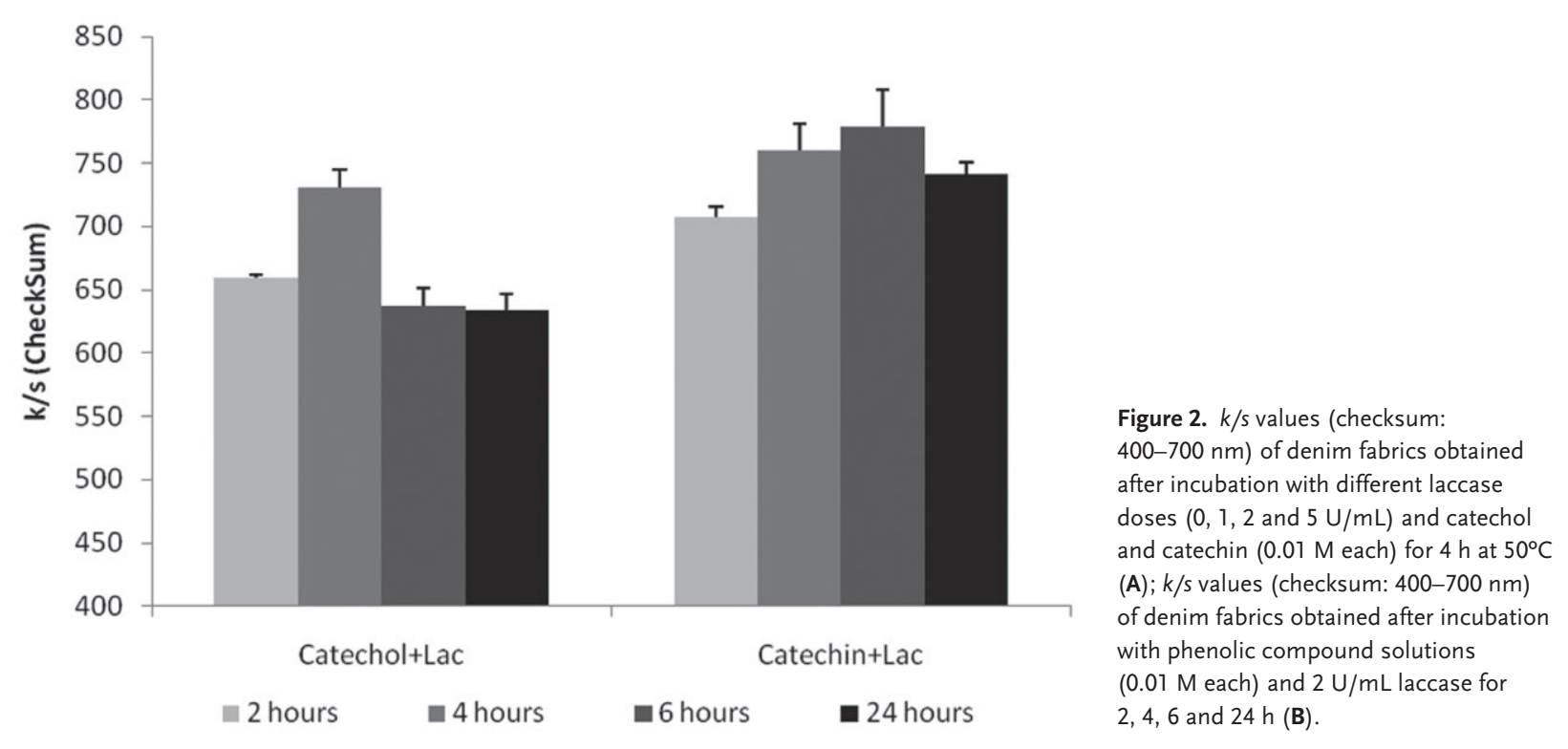

desorption phenomena have to be considered, since the system involves agitation and some soluble polymers formed can be dissolved. In the case of catechin, the behaviour is rather different. The highest level of overdyeing is obtained after incubation for $6 \mathrm{~h}$. It is important to consider that, in all of the cases presented, the level of overdyeing is always higher when catechin is used as the substrate (Fig. 2A and B). Catechin is, therefore, a superior substrate for enzyme oxidation, as presented in Fig. 1 , and has a higher affinity to denim cotton fabrics than catechol. The behaviour in terms of colour and shade variation of denim samples incubated with catechin in the presence of laccase under optimised conditions was evaluated. The $\mathrm{k} / \mathrm{s}$ of the overdyed samples and respective controls was es- timated at the right (warp) and reverse sides (weft) by using a Datacolor apparatus at standard illuminant D65 and Eq. (1) [25, 26]. The data (not shown) are the sum of all $\mathrm{k} / \mathrm{s}$ values obtained at the wavelength range $400-700 \mathrm{~nm}$. The measurements were done in triplicate and the data presented are the mean values of all measurements. Denim fabric used as a control, warp dyed with indigo, showed maximum colour absorbance $(k / s=13)$ at around $640 \mathrm{~nm}$. The enzymatic overdyed denim fabrics with phenolic polymers had a maximum absorbance at $400 \mathrm{~nm}(k / s=27.3)$, but a considerable increase at $640 \mathrm{~nm}$ was also detected $(k / s=24)$. The reverse of the denim fabrics was also estimated in terms of colour strength to verify the real polymer affinity (data not shown). A considerable increase 
Table 1. Washing and rubbing fastness of samples overdyed with catechol and catechin in the presence of laccase; the evaluation of each testimony fibre was based on (1) very poor washing resistance to (5) excellent washing resistance; the assay was performed with (P) and without sodium perborate (NP); the evaluation of the colour difference between samples was given by the spectrophotometer; the rubbing fastness evaluation was performed on right side $(r)$, and reverse side $(R)$ of the denim samples for dry and wet states; samples without laccase addition were used as controls

\begin{tabular}{|c|c|c|c|c|c|c|c|c|c|c|c|c|c|c|c|c|c|c|}
\hline \multirow[t]{3}{*}{ Samples } & \multicolumn{12}{|c|}{ Staining level (washing fastness) } & \multirow{2}{*}{\multicolumn{2}{|c|}{$\begin{array}{c}\text { Colour } \\
\text { difference }\end{array}$}} & \multicolumn{4}{|c|}{$\begin{array}{c}\text { Staining level } \\
\text { (rubbing fastness) }\end{array}$} \\
\hline & \multicolumn{2}{|c|}{ Acetate } & \multicolumn{2}{|c|}{ Cotton } & \multicolumn{2}{|c|}{ Polyamide } & \multicolumn{2}{|c|}{ Polyester } & \multicolumn{2}{|c|}{ Acrylic } & \multicolumn{2}{|c|}{ Wool } & & & \multicolumn{2}{|c|}{ Dry } & \multicolumn{2}{|c|}{ Wet } \\
\hline & NP & $\mathbf{P}$ & NP & $\mathbf{P}$ & $\mathbf{P}$ & $\mathbf{P}$ & NP & $\mathbf{P}$ & NP & $\mathbf{P}$ & NP & $\mathbf{P}$ & NP & $\mathbf{P}$ & $r$ & $\mathbf{R}$ & $r$ & $\mathbf{R}$ \\
\hline Control & 2 & $1 / 2$ & 4 & $3 / 4$ & $3 / 4$ & $3 / 4$ & $4 / 5$ & $4 / 5$ & $4 / 5$ & $4 / 5$ & $4 / 5$ & $4 / 5$ & $4 / 5$ & $4 / 5$ & $3 / 4$ & $4 / 5$ & 2 & $2 / 3$ \\
\hline Catechol/laccase & 2 & $1 / 2$ & 4 & $3 / 4$ & $3 / 4$ & $3 / 4$ & $4 / 5$ & $4 / 5$ & $4 / 5$ & $4 / 5$ & $4 / 5$ & $4 / 5$ & $4 / 5$ & $4 / 5$ & $3 / 4$ & $3 / 4$ & 2 & 2 \\
\hline Catechin/laccase & 2 & $1 / 2$ & 4 & $3 / 4$ & $3 / 4$ & $3 / 4$ & $4 / 5$ & $4 / 5$ & $4 / 5$ & $4 / 5$ & $4 / 5$ & $4 / 5$ & $4 / 5$ & $4 / 5$ & $3 / 4$ & $3 / 4$ & 2 & 2 \\
\hline
\end{tabular}

in the absorbance at $400 \mathrm{~nm}(k / s=23)$ was observed, corresponding to the increase in yellow colour. These results are explained by the fact that the reverse side is composed mainly of the filling yarns, which are not coloured with indigo dye. Moreover, an increase in absorbance at all areas of measurement was detected, meaning that the total colour of the sample changed.

Colour values $\left(L^{*}\right.$ and $\left.a^{*}, b^{*}\right)$ of natural phenolic compounds in aqueous solution were very similar to those in distilled water, indicating that phenolic compounds are poor absorbers of visible light. However, addition of laccase to samples containing single monomers or pairs of monomers resulted in visible colour generation. In general, $L^{*}$ (luminosity) values were evenly distributed from 0 (black) to 100 (white), but $a^{*}$ and $b^{*}$ values were negative and positive for right and reverse sides, respectively, indicating that green and yellow polymers were barely achieved by laccase-based polymerisation of the naturally occurring phenols tested herein (right side: $L^{*}=16,63, a^{*}=-0,98 b^{*}=$ $-0,51$; reverse side: $\left.L^{*}=33,56, a^{*}=1,19 b^{*}=15,15\right)$. The formed polymers gave different colourations of the denim fabric on the right and reverse sides, mostly green and yellow respectively, and contributed to the increase in the total colour of the denim samples on both sides of the sample (right side: $\Delta E^{*}: D_{65 / 10}=8.91$; reverse side: $\Delta E^{*}: D_{65 / 10}=$ 23,196).

As cited by several authors, mediators can effectively enhance laccase oxidation activity, making it able to oxidise not only reactive species, but also non-reactive ones [27]. Thus, the effect of syringaldehyde $(0.001 \mathrm{M})$ on the enzymatic overdyeing of denim was tested. This product is a natural mediator derived from lignin, which has been researched as an eco-friendly alternative to synthetic mediators [28]. The effect of this mediator was only detected on the enzymatic oxidation of catechol when an increase of $2.5 \%$ of colour strength was observed. In the case of catechin, syringaldehyde produced a negative effect. A colour decrease of $7 \%$ was observed with respect to control denim samples (data not shown).

The durability of attached polymers to denim fabrics was tested in terms of washing fastness, friction fastness, and light-exposure resistance. The washing fastness tests were performed by following the ISO 105-C06 standard method with and without sodium perborate [29]. This product is normally used in the detergent industry as a bleaching agent. The results presented in Table 1 were obtained by evaluating the level of staining of each fibre. For almost all of the fibres, a good level of washing fastness was achieved (4/5). Moreover, no significant differences were observed for samples washed in the presence or absence of sodium perborate. Laccase-generated polymers do not have an affinity to cellulose surfaces and do not covalently attach to these surfaces. Thus, the fixation of polymer molecules generated in situ on the fibre surface could take place due to a decrease in solubility, thereby preventing their release during wet treatments. These results corroborate the assumption that, after enzymatic oxidation, the polymers formed became insoluble their durability at the fibre's surface was acceptable for textile garment purposes.

The wet and dry overdyed samples were also tested in terms of rubbing fastness by following the standard test method using a crockmeter: ASTM D2054-99 [30] and the results are in agreement with previous ones. For the dry state, the level was good (3/4) for both right and reverse sides. For the wet state, rubbing fastness decreased considerably due to the water solubilisation of the more surfaceexposed polymers. However, and considering the high appetence of indigo to come out from fabrics during washing, the results obtained can be considered quite satisfactory, since the amount of poly- 
mer at the denim surface does not increase the normal level of staining.

After light exposure cycles of 8 or $24 \mathrm{~h}$, the light fastness of denim fabrics $(75 \times 150 \mathrm{~mm})$ was evaluated until remarkable colour degradation was observed. The overdyed samples presented colour degradation after $40 \mathrm{~h}$ of exposure (data not shown).

For short periods of light exposure $(8 \mathrm{~h})$, this degradation was lower than $5 \%$ for all samples, including the control. Moreover, overdyed samples with catechin presented lower degradation after $8 \mathrm{~h}$ of exposure, when compared with control samples $(1.56 \%$ for catechin/laccase and $4.22 \%$ for control samples), meaning that some indigo protection might have occurred. Catechin created a barrier between indigo and light, hindering oxidation of the dye. Since flavonoids are quite resistant to light, it seems clear that the degradation upon light exposure is due to the low indigo light resistance.

The impact of polymer attachment on the resistance of denim fabrics was evaluated in terms of tensile strength and elongation by following the procedure NP EN ISO 13934-1:2001 - Tensile properties of fabrics - Part 1: Determination of maximum force and elongation at maximum force using the strip method [31].

The deposition of new polymers at the surface of denim did not change significantly the tensile strength of both warp and weft yarns. Compared with the controls, the samples incubated with catechol and catechin in the presence of laccase revealed a decrease of 0.16 and $1.34 \%$ in tensile strength, respectively, in the weft direction. In the warp direction no significant changes were measured. Considering elongation, a slight decrease was also observed in the direction of the weft yarns, 3.67 and $1.95 \%$ for catechol and catechin, respectively, in the presence of laccase (data not shown). All of these results highlight the fact that the tensile strength performance of denim samples is maintained in acceptable levels after overdyeing with catechol and catechin, and hence, the integrity of the fabrics is preserved.

As mentioned before, laccase-generated polymers have insoluble character, giving rise to products with hydrophobic behaviour. Thus, their application at the denim surface would increase fabric's hydrophobicity. An increase $\left(+5.2^{\circ}\right)$ in the water CA of samples incubated with catechol and catechin in the presence of laccase was observed. The hydrophobic character of denim was enhanced by polymer deposition at fabric's surface, giving rise to new products with particular properties for special applications.

\section{Concluding remarks}

In this study, a successful process for enzymatic denim overdyeing was developed. Laccase, used as the catalyst, was able to oxidise the polymerisation in situ of catechol and catechin compounds. The enzyme-generated polymers showed the ability to be used as substitutes for direct dyes for denim overdyeing. Upon enzymatic overdyeing, denim fabrics reached different coloration, depending on the phenol used, ranging from brown to green-yellow, for catechol and catechin, respectively. The optimum processing parameters were set, considering the highest overdyeing level and the lowest energy/products consumption. Thus, $2 \mathrm{U} / \mathrm{mL}$ of laccase at $50^{\circ} \mathrm{C}$ in acetate buffer for $4 \mathrm{~h}$ of incubation were able to oxidise $0.01 \mathrm{M}$ of phenolics. High levels of laccase-generated polymer attachment were achieved without compromising the integrity of the denim cotton fabrics. The use of a mediator was not effective, since low levels of polymerisation were achieved. The enzymatic overdyeing with catechol and catechin opens up new strategies for denim overdyeing with the same level of durability as that obtained with direct dyes, increasing, at the same time, the fabric's hydrophobicity, imperative for specific applications.

S.Y.K. would like to acknowledge the BIORENEW European Project - Sixth Framework European Program. C.S. would like to acknowledge the Portuguese Fundação para a Ciência e a Tecnologia (FCT) for funding under the scholarship SFRH/BPD/46515/ 2008.

The authors have declared no conflict of interest.

\section{References}

[1] Dixon, M. W., Treatment of Textiles. Patent number 5,460,966 Sandoz, Switzerland 1995.

[2] Barfoed M., Kirk, O., Enzymatic method for overdyeing warp dyed denim textiles. Patent number 5,925,148 Sandoz, Novo Nordisk, Denmark 1999.

[3] Montazer, M., Sadeghian Maryan, A., Influences of Different Enzymatic Treatment on Denim Garment. Appl. Biochem. Biotechnol., 2010, 160, 2114-2128.

[4] Gusakov, A. V., Sinitsyn, A. P., Markov, A. V., Sinitsyna, O. A. et al., Study of protein adsorption on indigo particles confirms the existence of enzyme-indigo interaction sites in cellulase molecules. J. Biotechnol. 2001, 87, 83-90.

[5] PazarlIoglu, N. K., Sariisik, M., Telefoncu, A., Laccase: Production by Trametes versicolor and application to denim washing. Process Biochem. 2005, 40, 1673-1678.

[6] Catoira, L., Jeans, a roupa que transcende a moda, Idéias \& Letras, Aparecida, 2006. 
[7] Pazarlioglu, N. K., Sariisik, M., Telefoncu, A., Treating denim fabrics with immobilized commercial cellulases. Process Biochem. 2005, 40, 767-771.

[8] Burton, S. G., Laccases and phenol oxidases in organic synthesis - a Review. Curr. Org. Chem. 2003, 7, 1317-1331.

[9] Uyama, H., Kobayashi, S., Enzymatic Synthesis and Properties of Polymers from Polyphenols. in: Kobayashi, S., Ritter, H., Kaplan, D., Uyama, H. (Eds.) Enzyme-Catalyzed Synthesis of Polymers, Springer, Heidelberg, 2006, pp. 51-67.

[10] Aktas, N., Sahiner, N., Kantoglu, Ö., Salih, B., Tanyolaç, A., Biosynthesis and characterization of laccase catalyzed poly(catechol). J. Polym. Environ. 2003, 11, 123-128.

[11] Mita, N., Tawaki, S. i., Uyama, H., Kobayashi, S., Laccase-catalyted oxidative polymerization of phenols. Macromol. Biosci. 2003, 3, 253-257.

[12] Gianfreda, L., Sannino, F., Rao, M. A., Bollag, J. M., Oxidative transformation of phenols in aqueous mixtures. Water Res. 2003, 37, 3205-3215.

[13] Shin, H., Guebitz, G., Cavaco-Paulo, A., "In situ” enzymatically prepared polymers for wool coloration. Macromol. Mater. Eng. 2001, 286, 691-694.

[14] S.G., B., Laccases and phenol oxidases in organic synthesis - a review. Curr. Org. Chem. 2003, 7, 1317-1331.

[15] Witayakran, S., Ragauskas, A., Synthetic applications of laccase in green chemistry. Adv. Synthesis Catal., 2009, 351, 1187-1209.

[16] Hosny, M., Rosazza, J. P. N., Novel oxidations of (+)-catechin by horseradish peroxidase and laccase. J. Agric. Food Chem. 2002, 50, 5539-5545.

[17] Ma, H.-L., Kermasha, S., Gao, J.-M., Borges, R. M., Yu, X.-z., Laccase-catalyzed oxidation of phenolic compounds in organic media. J. Mol. Catal. B: Enzym. 2009, 57, 89-95.

[18] Osman, A. M., Wong, K. K. Y., Fernyhough, A., The laccase/ ABTS system oxidizes (+)-catechin to oligomeric products. Enzyme Microb. Technol. 2007, 40, 1272-1279.

[19] Tseitlin, G., Beksaev, S., Medzhitov, D., Enzymatic polymerization of phenols. Polymer Science Series A 2006, 48, 798802 .
[20] Kim, S., Moldes, D., Cavaco-Paulo, A., Laccases for enzymatic colouration of unbleached cotton. Enzyme Microb. Technol. 2007, 40, 1788-1793.

[21] Kim, S. L., C.; Güebitz, G.; Cavaco-Paulo, A., Biological coloration of flax fabrics with flavonoids using laccase from Trametes hirsuta. Eng. Life Sci. 2008, 8, 324-330.

[22] Hadzhiyska, H., Calafell, M., Gibert, J., Dagà, J., Tzanov, T., Laccase-assisted dyeing of cotton. Biotechnol. Lett. 2006, 28, 755-759.

[23] Schroeder, M., Aichernig, N., Guebitz, G. M., Kokol, V., Enzymatic coating of lignocellulosic surfaces with polyphenols. Biotechnol. J. 2007, 2, 334-341.

[24] Mai, C., Majcherczyk, A., Hüttermann, A., Chemo-enzymatic synthesis and characterization of graft copolymers from lignin and acrylic compounds. Enzyme Microb. Technol. 2000, 27, 167-175.

[25] Harold, R. W., Textile: appearance analysis and shade sorting. Textile Chemical Colouration, 1987, 19, 23-31.

[26] Mc Donald, R., Colour Physic for Industry. Society of Dyers and Colourists, 1987.

[27] Claus, H., Laccases: structure, reactions, distribution. $\mathrm{Mi}$ cron, 35, 93-96.

[28] Camarero, S., Ibarra, D., Martinez, M. J., Martinez, A. T., Lignin-derived compounds as efficient laccase mediators for decolorization of different types of recalcitrant dyes. Appl. Environ. Microbiol. 2005, 71, 1775-1784.

[29] ISO 105-C06:2010 Textiles - tests for colour fastness - part C06: Colour fastness to domestic and commercial laundering.

[30] ASTM D2054-99(2010) Standard test method for colorfastness of zipper tapes to crocking.

[31] ISO 13934-1:1999: Textiles - tensile properties of fabrics part 1: Determination of maximum force and elongation at maximum force using the strip method. 